\title{
Fibromiyaljili Kadınlarda Aktivite Performansı, Yaşam Memnuniyeti, Özür ve Ruhsal Durum İlişkilerinin İncelenmesi
}

Investigation of Occupational Performance, Life Satisfaction, Disability and Mental State Relationships in Women with Fibromyalgia

Gamze EKICi ${ }^{1}$, Aylin ÖNDEŞ ${ }^{2}$, Özgür BÜLBÜL ${ }^{3}$

${ }_{1}^{1}$ Prof. Dr., Hacettepe Üniversitesi Sağlık Bilimleri Fakültesi Ergoterapi Bölümü, Ankara, Türkiye

${ }^{2}$ Erg., Hacettepe Üniversitesi Sağlık Bilimleri Fakültesi Ergoterapi Bölümü, Ankara, Türkiye

${ }^{3}$ Uzm. Opr. Dr., Ankara Türk Telekom Sağlık Hizmetleri Müdürlüğü, Ankara, Türkiye

\section{öz}

\begin{abstract}
Amaç: Bu çalışma, fibromiyaljili kadınlarda aktivite performansı, yaşam memnuniyeti, özür ve ruhsal durum ilişkilerinin incelenmesi amacıyla planlandı. Gereç ve Yöntem: Çalışmaya, 47 Fibromiyalji Sendrom'lu (FMS) kadın dahil edilerek sosyodemografik bilgileri kaydedildi. Bireylerin aktivite performansları Kanada Aktivite Performans Ölçümü, yaşam memnuniyetleri Yaşam Memnuniyeti Anketi, ruhsal durum Hastane Anksiyete Depresyon Skalası ve özür Yeniden Gözden Geçirilmiş Fibromiyalji Etki Anketi (YFEA) ile değerlendirilerek bu parametreler arasındaki ilişkiler incelendi. Sonuçlar: Elde edilen bulgular doğrultusunda, YFEA'ya göre semptomlar arttıkça anksiyete $(r=0.440, p=0.002)$ ve depresyon $(r=0.290, p=0.048)$ bulgularının olumsuz etkilendiği; ayrıca bireylerin aktivite memnuniyetleri ile anksiyete bulguları $(r=0.298, p=0.042)$ ve toplam YFEA'ya göre FMS'nin oluşturduğu özür düzeyi ile depresyon bulguları arasındaki korelasyon $(r=0.302, p=0.039)$ ortaya koyuldu. Aynı zamanda, yaşam memnuniyeti ile hem FMS semptomlarının ( $r=-0.312, p=0.033)$ hem de depresyon bulgularının $(r=-0.391, p=0.007)$ negatif yönde ilişkili olduğu görüldü. Tartışma: Semptomlar şiddetlendikçe, aktivite ve yaşamdan duyulan memnuniyet azaldıkça FMS'li kadınlarda ruhsal durumun olumsuz etkilendiğini gördük. Dolayısıyla FMS semptomlarına odaklanırken, ruhsal durumun gözden kaçırılmaması gerektiği sonucuna varıldı. Ortaya koyulan bu ilişkilere rağmen geniş örneklem gruplarının dahil edileceği ileri çalışmalara intiyaç vardır.
\end{abstract}

Anahtar Kelimeler: Fibromiyalji; Aktiviteler; Memnuniyet

\section{ABSTRACT}

Purpose: The aim of this study was to investigate the relationship between occupational performance, life satisfaction, disability and mental status in women with fibromyalgia. Material and Methods: 47 women with Fibromyalgia Syndrome (FMS) were included in the study and their sociodemographic data were recorded. Occupational performance, life satisfaction, emotional status and disability of individuals were evaluated by Canada Occupational Performance Measurement, Satisfaction with Life Scale, Hospital Anxiety Depression Scale and The Revised Fibromyalgia Impact Questionnaire (FIQR), respectively and correlations were analyzed between these parameters. Results: According to the findings, in FIQR while symptoms increased, anxiety $(r=0.440, p=0.002)$ and depression $(r=0.290, p=0.048)$ symptoms were negatively affected; in addition, the correlations between the occupational satisfaction of the individuals and the anxiety findings $(r=0.298, p=0.042)$; and the level of disability created by FMS according to total FIQR, and depression findings $(r=0.302, p=0.039)$ were revealed. Both FMS symptoms $(r=-0.312, p=0.033)$ and depression symptoms $(r=-0.391, p=0.007)$ negatively correlated with life satisfaction. Conclusion: We found that while the symptoms were exacerbated, occupational and life satisfaction levels were decreased, emotional status was negatively affected in women with FMS. When focusing on FMS symptoms, it was concluded that the mental state should not be overlooked. Despite these relations, further studies which include large sample groups are needed.

Keywords: Fibromyalgia; Occupations; Satisfaction 
Fibromiyalji sendromu (FMS), genellikle hiperaljezi ve allodini ile ilişkili olarak görülen yaygın ağrı ile karakterize multisistemik bir hastalıktır (Sindel, Saral ve Esmaeilzadeh, 2012). Yorgunluk, değişen uyku düzenleri, parestezi, anksiyete, sertlik, depresyon, baş ağrısı ve ellerde şişlik hissi gibi belirtiler mevcuttur (Wolfe, 2010; Muto, Sauer, Yuan ve ark, 2015). Dünya nüfusunda 20 ve 50 yaş arasındaki kişilerin \% 3 ile 6'sını etkileyen bu sağlık problemi, kadınlarda erkeklerden daha sık görülmektedir (Gonzalez, del Teso Rubio, Paniagua ve ark, 2015). Türkiye'de (Trabzon) 20-64 yaş grubunda 1930 kadın üzerinde yapılan bir tarama çalışması sonucunda kadınlarda FMS prevalansı \% 3,6 bulunmuştur (Topbas, Cakirbay, Gulec ve ark, 2005).

FMS tanısı için uzun yıllar boyunca, hassas nokta muayenesini esas alan American College of Rheumatology 1990 tanı kriterleri kullanılmaktadır. Bu kriterlere göre, FMS tanısı konulması için en az 3 ay süren yaygın ağrı öyküsü ve 18 hassas noktanın en az 11 'inde palpasyonla ağrı bulgusunun olması gerekmektedir (Çakır, 2015).

Ağrı, FMS'de görülen en karakteristik semptom olarak tanımlanmaktadır, FMS'li kadınlarda gün içinde artan ağrı dalgalanmaları görülmektedir (Rainville, 2002). Ağrıyı arttıran faktörler arasında statik postür, fiziksel yük, duygusal tetikleyiciler ve iklim değişiklikleri yer almaktadır (Rivera ve González, 2004). FMS'li bireylerde genel popülasyona kıyasla daha yüksek bir yorgunluk düzeyi vardır. Yorgunluk, sabah yataktan kalkarken ve günün ilerleyen saatlerinde daha sık görülmektedir. Yorgunluk, FMS'li kadınların aktivite performansını olumsuz yönde etkileyerek, günlük yaşam aktiviteleri sırasında yorgunluk düzeyinin artmasında tetikleyici rol oynamaktadır (Yunus, İnanıcı ve Aldağ, 1989).

Aktivite performansı kişisel bir deneyimdir ve kişi, çevre ve aktivite üçlüsünün dinamik etkileşimi sonucunda ortaya çıkar (Rose, Nelson ve Hardiman, 2016). Aktivite performans alanları genel olarak kendine bakım (kişisel bakım, fonksiyonel mobilite, toplumsal başarı aktiviteleri) iş ve üretkenlik (maaşlı/maaşsız iş, ev idaresi yönetimi, okul/oyun aktiviteleri) ve serbest zaman (aktif rekreasyon, pasif rekreasyon, sosyalizasyon aktiviteleri) aktivitesi olarak sınıflandırııır (Law, Baum ve Dunn, 2005).

Yapılan çok sayıda çalışmada FMS'li bireylerin fiziksel performans ve günlük aktivite düzeyleri sağlıklı kadınlardan ve genel popülasyondan daha düşük bulunmuştur (Culos-Reed ve Brawlwy, 2000; Mannerkorpi, Svantesson, Carlsson ve ark, 1999; Tüzün, Albayrak, Eker ve ark, 2004). Diğer çalışmalar, FMS'li kadınların fiziksel kapasitelerinin azaldığını doğrulamıştır (White, Speechley, Harth ve ark, 1999). FMS yürüyüş, araba kullanmak, giyinmek, temel vücut duruşlarını değiştirmek, vücut pozisyonunu korumak, nesneleri kaldırmak ve taşımak, serbest zaman gibi sosyal katılım için gerekli aktiviteleri etkilemektedir (Hieblinger, Coenen, Stucki ve ark, 2009).

FMS'nin, günlük yaşam aktiviteleri üzerindeki etkilerini araştıran bir çalışmada, bireylerin \% 25'inin kişisel bakımında, \% 60'ının hafif ev işleri, merdiven inmek, bir kilometre yürümek ve ağırlık kaldırmakta, $\% 90$ 'dan fazlasının ise ağır ev işleri yapmakta zorluk yaşadığı bulunmuştur (Jones, Rutledge, Jones ve ark, 2008).

Literatürde FMS ile psikolojik sendromlar arasındaki ilişkiyi destekler nitelikte çalışmalar bulunmaktadır. FMS'li kadınlarda yüksek düzeyde psikolojik stres ve farklı psikiyatrik bozukluklara rastlanmaktadır. FMS'nin psikolojik, duygusal, davranışsal ve fonksiyonel semptomlarının, özellikle büyük travmatik olaylardan sonra oluştuğu ve somatik şikayetler de belirgin bir artı̧̧ olduğu bildirilmiştir (Bellato, Marini, Castoldi ve ark, 2012).

Yapılan çalışmalar incelendiğinde bireyin tüm yaşamını içeren kendine bakım, serbest zaman ve üretkenlik alanlarındaki aktivite performans ve memnuniyetleri konusunda kısıtı sayıda çalışma olduğu belirlenmiştir. FMS gibi bireyi pek çok açıdan etkileyen bir durumda kişinin yaşamının ne kadar etkilendiği ve ruhsal durumu arasındaki ilişkilere odaklanılmadığı görülmüştür. $\mathrm{Bu}$ nedenle bu çalışma, FMS'li kadınlarda aktivite performansı, yaşam memnuniyeti, özür, depresyon ve anksiyete bulguları arasındaki ilişkilerinin incelemesi amacıyla planlanmıştır.

\section{GEREÇ VE YÖNTEM}

Çalışmaya, 18-65 yaş aralığında FMS tanısı alan 47 kadın dahil edilmiştir. Çalışma, Eylül 2018-Haziran 2019 tarihleri arasında yapılmıştır. FMS'ye eşlik eden herhangi bir hastalık (kardiyopulmoner hastalık, obezite vb.), psikiyatrik hastalık (şizofreni, maddeyi kötüye kullanım vb.) ve endokrin bozuklukları (diyabet vb.) gibi hastalıkları bulunanlar çalışmaya dahil edilmemiştir. Çalışmaya katılan gönüllü bireylere çalışma hakkında bilgi verilip, kabul edenlere Helsinki Deklerasyon Prensiplerine uygun olarak çalışmanın amaç ve yöntemlerini belirten bilgilendirilmiş bir onam formu imzalatılmıştır. 
Veri Toplama Araçları

Sosyodemografik Bilgi Formu: FMS'li kadınların yaş (yıl), boy $(\mathrm{m})$, kilo $(\mathrm{kg})$, vücut kitle indeksi (vki), medeni durumu, eğitim durumu, çalışma durumu, mesleki durumu çocuk sayısı ve sigara içme durumu sorgulanarak kaydedilmiştir.

Kanada Aktivite Performans Ölçümü (KAPÖ): Kanada Ergoterapistleri Derneği tarafından geliştirilen, bireylerin problem yaşadığı performans alanlarının belirlenmesinde ve aktivite performans ile memnuniyet düzeyini belirlemeye yardımcı yarıyapılandırılmış bir ölçüm aracıdır. Ölçek, bireyin aktivite tercihlerini kendisi tarafından verilen performans ve memnuniyet puanları ile değerlendirir. Kendine bakım, üretkenlik ve serbest zaman olmak üzere üç bölümden oluşur. Değerlendirmenin ilk aşamasında birey tarafından belirlenen günlük yaşam aktiviteleri 1 ile 10 arasında (1: hiç önemli değil, 10: çok önemli) önem sırasına göre değerlendirilir. Diğer aşamada ise bireyden birey için en önemli beş aktiviteyi seçip her bir aktivite için yine likert ölçeğine göre 1 ile 10 arasında performans ve memnuniyet puanı belirlemesi istenir. (1: performansım çok kötü, 10: performansım çok iyi/1: hiç memnun olmuyorum, 10: çok memnun oluyorum). Elde edilen performans ve memnuniyet puanları toplanarak bireyin önemli olduğunu belirttiği aktivite sayısına bölünür ve performans ile memnuniyet puanları elde edilir (McColl, Law, Baptiste ve ark, 2005). Türkçe geçerlilik ve güvenilirlik çalışması tarafından yapılmıştır (Torpil, Ekici-Çağlar ve Bumin, 2018).

Yaşam Memnuniyeti Anketi: Diener ve arkadaşları 1985 tarafından geliştirilen Yaşam Memnuniyeti Ölçeği 5 maddeden oluşmaktadır. Tek boyutlu olan bu ölçek, 7'li likert tipi bir derecelendirmeye ("1" Kesinlikle katılmıyorum - "7" Kesinlikle katılıyorum) sahiptir (Diener, Emmons, Larsen ve ark, 1985). Psikometrik özellikleri Durak ve ark. tarafından incelenmiştir (Durak, Senol-Durak ve Gencoz, 2010).

Yeniden Gözden Geçirilmiş Fibromiyalji Etki Anketi (YFEA): YFEA, fonksiyon, genel ve semptomlar olmak üzere üç bölümde toplam 21 soru ile FMS'li bireylerde oluşan limitasyonları ve fonksiyonel disabiliteyi değerlendiren bir ankettir. Bütün sorular 0-10 arasında numerik skala ile değerlendirilmektedir. Anketten elde edilen puan yükseldikçe FMS'ye bağlı disabilitenin arttığını gösterir. Türkçe geçerlilik ve güvenilirlik çalışması Ediz ve arkadaşları tarafından yapılmıştır (Ediz, Hiz, Toprak ve ark, 2011).

Hastane Anksiyete ve Depresyon Skalası (HADS): Zigmond ve arkadaşları tarafından geliştirilen 7'si anksiyete, 7'si depresyon belirtilerini araştıran toplam 14 maddeden oluşan Türkçe geçerlilik ve güvenilirliği olan bir ölçektir. Yanıtlar dörtlü likert biçiminde değerlendirilmektedir ve 0-3 puan arasında puanlanmaktadır. Ölçeğin amacı fiziksel hastalığı olanlarda anksiyete ve depresyonu kısa sürede tarayarak risk grubunu belirlemektir. Anksiyete için kesme puanı 10/11, depresyon için kesme puanı 7/8. Buna göre bu puanların üzerinde alanlar anksiyete ve depresyon açısından risk altında olarak değerlendirilir. Türkçe geçerlilik ve güvenilirlik çalışması Aydemir tarafından yapılmıştır (Zigmond ve Snaith,1983; Aydemir, 1997).

\section{İstatiksel Analiz}

Verilerin istatistiksel analizlerinde SPSS 18.00 programı kullanılmıştır. Bireylerin sosyodemografik özellikleri, yaş (yıl), boy (m), kilo (kg), vücut kitle indeksi (vki) medeni durumu, eğitim, sigara ve çocuk sayısı gibi tanımlayıcı verilerde uygunluğuna göre frekans ve/veya ortalama \pm Standart Sapma (X $\pm S S$ ) değerleri verilmiştir. KAPÖ, Yaşam Memnuniyeti, YFEA ve HADS için elde edilen değerler 'Spearman Korelasyon Analizi' kullanılarak incelenmiştir. İstatistiksel anlamlılık düzeyi $p<0,05$ olarak kabul edilmiştir.

\section{SONUÇLAR}

Dahil edilen bireylerin ortalama yaşı $40,87 \pm 9,44$ yıl (minimum: 19 yıl, maksimum: 65 yıl) olarak kaydedilmiştir. Tablo 1'de bireylerin sosyodemografik özellikleri verilmiştir.

KAPÖ, Yaşam memnuniyeti, YFEA, HADS ortalama değerleri ve standart sapmaları Tablo 2'de gösterilmiştir.

FMS'li kadınlarda FMS'ye dair semptomları arttıkça depresyon $(r=0.290 p=0.048)$ ve anksiyete $(r=0.440, p=0.002)$ düzeyleri de artmaktır. Bireyleri aktivite memnuniyetleri arttıkça anksiyete $(r=0.298$, $p=0.042$ ) bulguları azalmaktadır. FMS'li kadınların yaşam memnuniyetleri arttıkça FMS'ye ait semptomlar $(r=0.312, \quad p=0.033)$ ve depresyon düzeyleri $\quad(r=0.391, \quad p=0.007) \quad$ azalmaktadır. Paremetreler arası korelasyonlar Tablo 3'te sunulmuştur. 
Tablo 1. Katılımcıların sosyodemografik bilgileri $(n=47)$

\begin{tabular}{|c|c|}
\hline Sosyodemografik Özellikler & n (\%) \\
\hline \multicolumn{2}{|l|}{ Medeni Durum } \\
\hline Bekar & $10(21,3)$ \\
\hline Evli & $34(72,3)$ \\
\hline Dul & $3(6,4)$ \\
\hline \multicolumn{2}{|l|}{ Eğitim } \\
\hline İlkokul & $15(31,9)$ \\
\hline Ortaokul & $5 \quad(10,6)$ \\
\hline Lise & $12(25,5)$ \\
\hline Lisans & $11(23,4)$ \\
\hline Yüksek lisans & $4 \quad(8,5)$ \\
\hline \multicolumn{2}{|l|}{ Sigara } \\
\hline Evet & $9(19,1)$ \\
\hline Hayır & $37(78,7)$ \\
\hline Kullanmıyor & $1(2,1)$ \\
\hline \multicolumn{2}{|l|}{ Çocuk Sayısı } \\
\hline 0 & $5 \quad(10,6)$ \\
\hline 1 & $12(25,5)$ \\
\hline 2 & $22(46,8)$ \\
\hline 3 & $3(6,4)$ \\
\hline 4 & $3(6,4)$ \\
\hline $5+$ & $2(4,3)$ \\
\hline & $X \pm S S$ \\
\hline Yaş (yıl) & $40,87 \pm 9,44$ \\
\hline Boy $(\mathrm{cm})$ & $161,72 \pm 7,39$ \\
\hline Kilo (kg) & $66,82 \pm 10,77$ \\
\hline VKI $\left(\mathrm{kg} / \mathrm{m}^{2}\right)$ & $25,50 \pm 4,18$ \\
\hline
\end{tabular}

Tablo 2. Bireylerin aktivite performansı, yaşam memnuniyeti, özür ve ruhsal durum ortalama puanları(n=47)

\begin{tabular}{|c|c|}
\hline & $X \pm$ SS \\
\hline \multicolumn{2}{|c|}{ Kanada Aktivite Performansı Ölçeği (KAPÖ) } \\
\hline KAPÖ Performans (0-10) & $4,98 \pm 1,17$ \\
\hline KAPÖ Memnuniyet (0-10) & $3,80 \pm 1,63$ \\
\hline Yaşam Memnuniyet Anketi (7-35) & $21,76 \pm 5,12$ \\
\hline \multicolumn{2}{|c|}{ Yeniden Gözden Geçirilmiş Fibromiyalji Etki Anketi (YFEA) } \\
\hline YFEA Fonksiyon (0-30) & $12,55 \pm 7,03$ \\
\hline YFEA Semptomlar (0-20) & $25,23 \pm 7,35$ \\
\hline YFEA Genel (0-50) & $10,48 \pm 5,95$ \\
\hline \multicolumn{2}{|c|}{ Hastane Anksiyete ve Depresyon Skalası (HADS) } \\
\hline HADS-Depresyon (0-21) & $9,04 \pm 3,01$ \\
\hline HADS-Anksiyete (0-21) & $9,31 \pm 3,19$ \\
\hline
\end{tabular}


Tablo 3. Kanada Aktivite Performansı Ölçeği, Yaşam Memnuniyeti Anketi, Yeniden Gözden Geçirilmiş Fibromiyalji Etki Anketi, Hastane Anksiyete ve Depresyon Skalası parametreleri arasındaki ilişki $(n=47)$

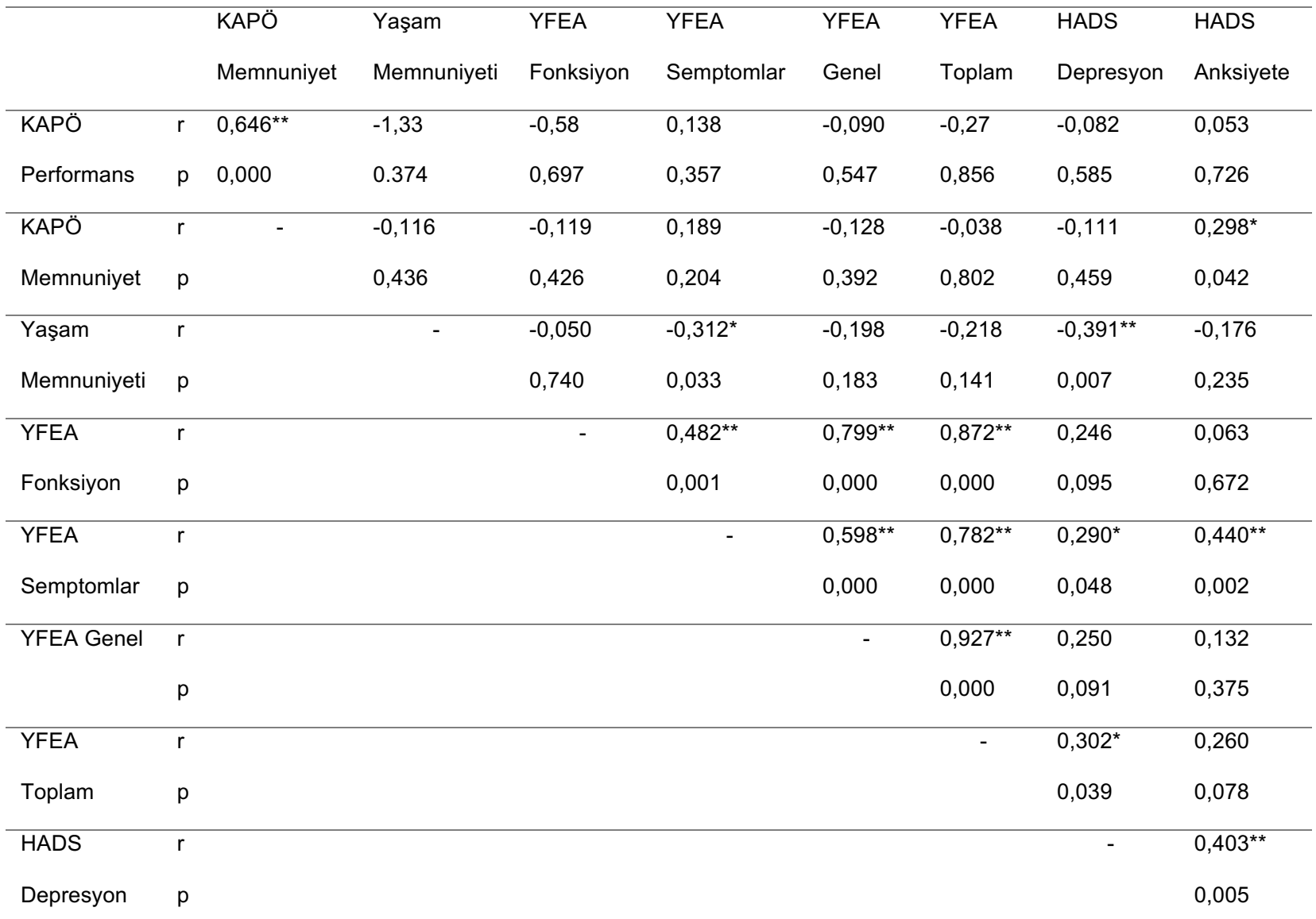

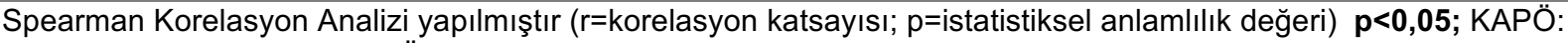
Kanada Aktivite Performans Ölçümü, YFEA: Yeniden Gözden Geçirilmiş Fibromiyalji Etki Anketi, HADS: Hastane Anksiyete Depresyon Skalası

\section{TARTIŞMA}

FMS'li kadınların aktivite performansı, yaşam memnuniyeti, özür ve ruhsal durumları arasındaki ilişkileri incelenmek amacıyla yapılan bu çalışmada, FMS semptomları, yaşam memnuniyeti, anksiyete ve depresyon bulguları arasında ilişki olduğu tespit edilmiştir.

FMS'li kadınlarda, yorgunluk, bitkinlik, ağrı eşiğinin düşmesinden dolayı, günlük yaşam aktivitelerinin yapmama eğilimindedirler. Aktiviteye katılım kısıtııı̆ı FMS'li kadınların fonksiyonel kapasitelerini olumsuz yönde etkilemektedir. FMS, bireyin aktivite performans alanlarını olumsuz yönde etkileyen bir sendrom haline gelmektedir (Kasikcioglu, Dinler ve Berker, 2006; Raj ve Paradise, 2004; Goldenberg, Burckhardt ve Crofford, 2004). Bizim çalışmamızda, literatüre benzer olarak kişilerin aktivite düzeyleri arttıkça FMS semptomlarının da artığı tespit edilmektedir.

Çalışmalar, FMS'li bireylerin yürüme, merdiven çıkma ve objelerin taşınmasını gerektiren aktivitelerde zorlandıklarını göstermektedir (Alkan, 2006). Yaptığımız bu çalışma da FMS'li kadınlarda özellikle poşet taşıma, merdiven inip-çıkma, uzun mesafe de yürüme gibi birçok aktiviteleri zorlandıklarını ortaya koymaktadır.

Bireyler günlük yaşam sırasındaki fonksiyonelliğin artışına bağlı olarak kendilerini daha iyi hissetmektedir ve Bu durum bireylerin anksiyete ve depresyon bulgularının azalmasını neden olmaktadır. Bizim çalışmamızda, FMS'li kadınların günlük yaşamda fonksiyonelliğinin artmasıyla depresyon ve anksiyete bulgularının azaladığı görülmektedir.

FMS, kişinin fonksiyonel kapasitesinde ve günlük yaşam aktivitelerinde önemli zorluklara yol açarak yaşam memnuniyetini bozmaktadır. Litaratüre bakıldığında Mesci ve arkadaşlarının (2015) yaptığı çalışmada FMS'li kadınların yaşam memnuniyeti düzeylerinin düşük olduğu 
gözlenmektedir. FMS'ye ait semptomlarının, FMS'li kadınların günlük yaşam aktivitelerinin olumsuz yönde etkilediği ve yaşam memnuniyetlerinin azaldığı gözlemlenmiştir (Birtane, Uzunca, Taştekin ve ark, 2007; Chorus, Miedema, Boonen ve ark, 2003; Ozgül, Pekere, Taskaynatan ve ark, 2006; Davis, Van Der Heijde, Dougados ve ark, 2005; Walker ve Littlejohn, 2007; Salaffi, Carotti, Gasparini ve ark, 2009; Hoving, Bartelds, Sluiter ve ark, 2009; Zhu, Tam, Lee ve ark, 2008). Bu çalışmada bulduğumuz bulgular literatürle uyumlu olup FMS'li kadınların aktivite performansları FMS semptomları arttıkça olumsuz etkilendiği ve buna bağlı olarak yaşam memnuniyet düzeylerinin düşük olduğu bulunmuştur.

Kronik ağrının uzun dönemde ciddi ruhsal problemlere yol açığı bilinmektedir (Madenci, Herken, Yağız ve ark, 2006) yaptığı çalışmada FMS'nin duygu durum bozuklukları ile ilişkili olduğunu göstermektedir. Bu çalışmaya göre FMS'li kadınlarda depresyon ve anksiyete semptomları görülmektedir. Bizim çalışmamız da literatürle benzer sonuçlar göstererek kişilerin FMS sendromuna dair semptomları artıkça anksiyete ve depresyon düzeyleri de artmaktadır.

FMS gibi kronik hastalıklar, bireylerin fiziksel, psikolojik ve sosyal iyilik hallerini olumsuz etkilemektedir (Walker ve ark, 2007; Birtane ve ark, 2007; Zautra, Fasman, Parish ve ark, 2007). Ek olarak, bir çalışmada ağrının sağlıkla ilgili yaşam memnuniyetinin düşük olmasının en önemli nedeni olarak belirtilmiştir (Svendsen, Jensen, Hansen ve ark, 2005). Yaptığımız çalışma da ise literatürle uyumlu olarak FMS'ye ait semptomlar artıkça FMS'li kadınların depresyon ve anksiyete bulguları artmaktadır buna bağı olarak da yaşam memnuniyet düzeyleri düşmektedir.

Çalışmamızın limitasyonu, kadınlarda aktivite performansı, yaşam memnuniyeti, özür ve ruhsal durum ilişkileri açısından elde edilen bulgularla genelleme yapmak için daha geniş örneklem grubuna intiyaç olmasıdır. FMS için bütün olarak düşünüldüğünde gelecekte sadece erkek popülasyonun dahil edildiği çalışmaların yapılması ayrıca değerli olacaktır.

Sonuç olarak; kişilerin aktivite performansları arttıkça aktive memnuniyetleri artmaktadır, yaşam memnuniyeti arttıkça ise FMS semptomları ve depresyon düzeyleri azalmaktadır. Kişilerin fiziksel aktivite düzeyleri arttıkça FMS'ye dair semptomları artmaktadır, Bu semptomlara bağlı olarak anksiyete ve depresyon düzeyleri artmaktadır.

Çalışmamı gelecekte yapılacak olan
Ergoterapi çalışmalara yön gösterecek olmakla birlikte daha fazla FMS'li kadınların katılımıyla yapılması ve ek olarak çalışmaya erkek bireylerin de dahil edilmesi önerilmektedir.

\section{Kaynaklar}

Alkan, N. (2006). Fibromiyalji ve miyofasiyal ağrı sendromu olan kadınların fonksiyonel kapasiteleri ile fiziksel uygunluk düzeylerinin karşıllaştırılması. (Yüksek lisans tezi). Başkent Üniversitesi/Sağlık Bilimleri Enstitüsü, Ankara.

Aydemir, O., Güvenir, T., Küey L., \& Kültür, S. (1997). Hastane Anksiyete ve Depresyon Ölçeği Türkçe formunun geçerlilik ve güvenilirliği. Turk Psikiyatri Derg, 8, 187-280.

Bellato, E., Marini, E., Castoldi, F., Barbasetti, N., Mattei, L., Bonasia, D. E., \& et al. (2012). Fibromyalgia syndrome: etiology, pathogenesis, diagnosis, and treatment. Pain Res Treat, 2012(6), 426130. https://doi.org/10.1155/2012/426130

Birtane, M., Uzunca, K., Taştekin, N., \& Tuna, H. (2007). The evaluation of quality of life in fibromyalgia syndrome: A comparison with rheumatoid arthritis by using SF-36 Health Survey. Clinical Rheumatology, 26(5), 679-684. https://doi.org/10.1007/s10067-006-0359-2

Chorus, A. M. J., Miedema, H. S., Boonen, A., \& Van Der Linden, S. J. (2003). Quality of life and work in patients with rheumatoid arthritis and ankylosing spondylitis of working age. Ann Rheum Dis, 62(12), 1178-1184. https://doi.org/10.1136/ard.2002.004861

Clark, S. R., Burkhardt, C. S., Camphell, S., O'reilly, C., \& Bennet, R. M. (1993). Fitness characteristics and perceived exertion in women with fibromyalgia. $J$ Musculoskelet Pain, 1(3-4), 191-197. https://doi.org/10.1300/J094v01n03_19

Culos-Reed, S. N., \& Brawley, L. R. (2000). Fibromyalgia, physical activity and daily functioning. Arthritis Care Res, 13(6), 343-351.

Çakır, T. (2015). Fibromiyalji sendromunda tanı kriterleri. Turkiye Klinikleri J PM\&R-Special Topics, 8(3), 22-27.

Davis, J. C., Van Der Heijde, D., Dougados, M., \& Woolley, J. M. (2005). Reductions in health related quality of life in patients with ankylosing spondylitis and improvements with etanercept therapy. Arthritis Care Res, 53(4), 494501. https://doi.org/10.1002/art.21330

Diener, E. D., Emmons, R. A., Larsen, R. J., \& Griffin, S. (1985). The satisfaction with life scale. $J$ Pers Assess, 49(1), 71-75. https://doi.org/10.1207/s15327752jpa4901_13

Durak, M., Senol-Durak, E. \& Gencoz, T. (2010). Psychometric properties of the satisfaction with life scale among turkish university students, correctional officers, and elderly adults. Soc Indic Res, 99(3), 413-429.

Ediz, L., Hiz, O., Toprak, M., Tekeoglu, I., \& Ercan, S. (2011). The validity and reliability of the Turkish version of the Revised Fibromyalgia Impact Questionnaire. Clin Rheumatol, 30(3), 339-346. https://doi.org/10.1007/s10067-010-1546-8

Goldenberg, DL., Burckhardt, C., \& Crofford, L. (2004). 
Management of fibromyalgia syndrome. JAMA, 292(19), 2388-2385. https://doi.org/10.1001/jama.292.19.2388

Gonzalez, J. G., del Teso Rubio, M. D. M., Paniagua, C. N. W., Criado-Alvarez, J. J., \& Holgado, J. S. (2015). Symptomatic pain and fibromyalgia treatment through multidisciplinary approach for primary care. Reumatol Clin (English Edition), 11(1), 22-26. https://doi.org/10.1016/j.reumae.2014.03.019

Hieblinger, R., Coenen, M., Stucki, G., Winkelmann, A., \& Cieza, A. (2009). Validation of the International Classification of Functioning, Disability and Health Core Set for chronic widespread pain from the perspective of fibromyalgia patients. Arthritis Res Ther, 11(3), R67. https://doi.org/10.1186/ar2696

Hirshberg, L. L., Jaffer, A. M., Reid, R. T., \& Heaton, R. (2003, September). Absence of demonstrable cognitive abnormalities in fibromyalgia patients. Abstract in American College of Rheumatology Annual Meeting, Arthritis and Rheumatism, 48(9), S87.

Hoving, J. L., Bartelds, G. M., Sluiter, J. K., Sadiraj, K., Groot, I., Lems, W. F., \& et al. (2009). Perceived work ability, quality of life, and fatigue in patients with rheumatoid arthritis after a 6-month course of TNF inhibitors: prospective intervention study and partial economic evaluation. Scand J Rheumatol, 38(4), 246-250. https://doi.org/10.1080/03009740902748264

Jones, J., Rutledge, D. N., Jones, K. D., Matallana, L., \& Rooks, D. S. (2008). Self-assessed physical function levels of women with fibromyalgia: a national survey. Womens Health Issues, 18(5), 406-412. https://doi.org/10.1016/j.whi.2008.04.005

Kasikcioglu, E., Dinler, M., \& Berker, E. (2006). Reduced tolerance of exercise in fibromyalgia may be a consequence of impaired microcirculation initiated by deficient action of nitric oxide. Med Hypotheses, 66(5), 950-952. https://doi.org/10.1016/j.mehy.2005.11.028

Law, M.C., Baum, C.M., \& Dunn, W. (2005). Measuring occupational performance: Supporting best practice in occupational therapy (Second Edition). Thorofare NJ: Slack Incorporated.

Madenci, E., Herken, H., Yağız, E., Keven, S., \& Gürsoy, S. (2006). Kronik ağrılı ve fibromiyalji sendromlu hastalarda depresyon düzeyleri ve ağrı ile başa çıkma becerileri. Turk J Phys Med Rehabil, 52(1), 19-21.

Mannerkorpi, K., Svantesson, U., Carlsson, J., \& Ekdahl, C. (1999). Tests of functional limitations in fibromyalgia syndrome: a reliability study. Arthritis Care Res, 12(3), 193-199. https://doi.org/10.1002/15290131(199906)12:3<193::AID-ART6>3.0.CO;2-N

McColl, M. A., Law, M., Baptiste, S., Pollock, N., Carswell, A., \& Polatajko, H. J. (2005). Targeted applications of the Canadian Occupational Performance Measure. Can $J$ Occup Ther, 72(5), 298-300. https://doi.org/10.1177/000841740507200506

Mesci, E., Mesci, N., Yıldırım, P., \& İçağasıoğlu, A. (2015). Fibromiyaljili kadınlarda yalnızlık hissi ve yaşam doyumu düzeylerinin değerlendirilmesi. Kocaeli Tıp Dergisi, 4(2), 23-28. https://dergipark.org.tr/download/articlefile/513633

Muto, L. H., Sauer, J. F., Yuan, S. L., Sousa, A., Mango, P. C., \& Marques, A. P. (2015). Postural control and balance self-efficacy in women with fibromyalgia: are there differences?. Eur J Phys Rehabil Med, 51(2), 149-154.
Ozgül, A., Peker, F., Taskaynatan, M. A., Tan, A. K., Dinçer, K., \& Kalyon, T. A. (2006). Effect of ankylosing spondylitis on health-related quality of life and different aspects of social life in young patients. Clinical Rheumatology, 25(2), 168-174. https://doi.org/10.1007/s10067-005-1150-5

Rainville, P. (2002). Brain mechanisms of pain affect and pain modulation. Curr Opin Neurobiol, 12(2), 195-204. https://doi.org/10.1016/S0959-4388(02)00313-6

Raj, P. P., \& Paradise, L. A. (2004, September). Myofascial pain syndrome and its treatment in low back pain. Seminars in Pain Medicine, 2(3), 167-174. https://doi.org/10.1016/j.spmd.2004.09.002

Rivera, J., \& González, T. (2004). The Fibromyalgia Impact Questionnaire: a validated Spanish version to assess the health status in women with fibromyalgia. Clin Exp Rheumatol, 22(5), 554-560. https://www.clinexprheumatol.org/article.asp?a $=2388$

Rose, J., Nelson, L., \& Hardiman, R. (2016). The relationship between challenging behaviour, cognitions and stress in mothers of individuals with intellectual disabilities. Behav Cogn Psychother, 44(6), 691-704. https://doi.org/10.1017/S1352465816000242

Salaffi, F., Carotti, M., Gasparini, S., Intorcia, M., \& Grassi, W. (2009). The health-related quality of life in rheumatoid arthritis, ankylosing spondylitis, and psoriatic arthritis: a comparison with a selected sample of healthy people. Health Qual Life Outcomes, 7(1), 25. https://doi.org/10.1186/1477-7525-7-25

Sindel, D., Saral, I., \& Esmaeilzadeh, S. (2012). Management approaches in fibromyalgia syndrome/Fibromiyalji sendromunda uygulanan tedavi yöntemleri. Turk J Phys Med Rehabil, 58(2), 136-143.

Svendsen, K. B., Jensen, T. S., Hansen, H. J., \& Bach, F. W. (2005). Sensory function and quality of life in patients with multiple sclerosis and pain. Pain, 114(3), 473-481. https://doi.org/10.1016/j.pain.2005.01.015

Topbas, M., Cakirbay, H., Gulec, H., Akgol, E., Ak, I., \& Can, G. (2005). The prevalence of fibromyalgia in women aged 20-64 in Turkey. Scand J Rheumatol, 34(2), 140-144. https://doi.org/10.1080/03009740510026337

Torpil, B., Ekici-Çağlar, G., \& Bumin, G. (2018). Reliability and validity of the Canadian occupational performance measure in people with multiple sclerosis. JETR, 5(2), S68.

Tüzün, E. H., Albayrak, G., Eker, L., Sözay, S., \& Daşkapan, A. (2004). A comparison study of quality of life in women with fibromyalgia and myofascial pain syndrome. Disabil Rehabil, 26(4), 198-202. https://doi.org/10.1080/09638280310001639696

Walker, J. G., \& Littlejohn, G. O. (2007). Measuring quality of life in rheumatic conditions. Clinical Rheumatology, 26(5), 671-673. https://doi.org/10.1007/s10067-0060450-8

White, K. P., Speechley, M., Harth, M., \& Ostbye, T. (1999). Comparing self-reported function and work disability in 100 community cases of fibromyalgia syndrome versus controls in London, Ontario: the London Fibromyalgia Epidemiology Study. Arthritis Rheum, 42(1), 76-83. https://doi.org/10.1002/1529-0131(199901)42:1<76::AIDANR10>3.0.CO;2-G

Wolfe, F. (2010). New American College of Rheumatology criteria for fibromyalgia: A twenty year journey. Arthritis Care Res, 62(5), 583-584. 
https://doi.org/10.1002/acr.20156

Yunus, M. B., Inanici, F., \& Aldag, J. C. (1989). Fibromyalgia in men: Comparison of clinical features primary fibromyalgia syndrome: A controlled and blinded study. J Rheumatol, 16, 97-101.

Zautra, A. J., Fasman, R., Parish, B. P., \& Davis, M. C. (2007). Daily fatigue in women with osteoarthritis, rheumatoid arthritis, and fibromyalgia. Pain, 128(1-2), 128-135. https://doi.org/10.1016/j.pain.2006.09.004

Zhu, T. Y., Tam, L. S., Lee, V. Y., Hwang, W. W., Li, T. K., Lee, K. K., \& Li, E. K. (2008). Costs and quality of life of patients with ankylosing spondylitis in Hong Kong. Rheumatology, 47(9), 1422-1425.

https://doi.org/10.1093/rheumatology/ken287

Zigmond, A. S., \& Snaith, R. P. (1983). The hospital anxiety and depression scale. Acta Psychiatr Scand, 67(6), 361370. https://doi.org/10.1111/j.1600-0447.1983.tb09716.x 